\title{
The Cesàro Operator on Some Sequence Spaces in Riesz Space of Non- Absolute Type
}

\section{E. Herawati ${ }^{*}$ and Supama ${ }^{2}$}

${ }^{1}$ Department of Mathematics, Universitas Sumatera Utara, Medan, 20155, Indonesia

${ }^{2}$ Department of Mathematics, Universitas Gadjah Mada, Yogyakarta, 55281, Indonesia

\begin{abstract}
The Cesàro operators $C$ are investigated on the class $E$-valued sequence spaces $c_{0}(E), c(E)$ and $\ell_{\infty}(E)$ with $E$ is a Riesz space. Besides, we also carry out that $C$ are order bounded operators.

Keywords: Banach spaces, Bounded operator, Ideal, Regular operator, Riesz spaces.

Abstrak. Operator Cesàro $C$ diteliti atas kelas ruang barisan bernilai-E $c_{0}(E), c(E)$ dan $\ell_{\infty}(E)$ dengan E merupakan ruang Riesz. Selain itu, juga diperoleh bahwa C merupakan operator terbatas terurut.
\end{abstract}

Kata Kunci: Ruang Banach, Operator terbatas, Ideal, Operator regular, Ruang Riesz.

Received 04 August 2020 | Revised 29 August 2020 | Accepted 30 September 2020

\section{Introduction}

The operator that acting on sequences on functions based on an averaging process is called the Cesàro operator. This operator have been studied in a variety of Banach spaces [1, 2]. For the Fréchet spaces, that is generalization of Banach spaces, this operator also studied [3]. Moreover, by using the convergence topology in non-negative real number, the Cesàro operator studied in the real non-negative sequence spaces and in the quojection Fréchet spaces [4]. When $X$ has an order structure, Herawati [5] introduced space of sequence in $X$ and studied some properties by using the order convergence. In the present paper, by using the certain type of the space in [6]. We analyze the order continuous of the Cesàro operator and show this operators are order bounded.

Throughout the sequel, we denotes $E$ as a Riesz space and its cone positive by $E^{+}$. A Riesz space $E$ is called order complete, if every non-empty subset of $E$ has a supremum and an infimum. The notation $x_{n} \downarrow$ is used for decreasing sequence in $E$ and $x_{n} \downarrow x_{0}$ proved $x_{n} \downarrow$ and $\inf \left(x_{n}\right)=x_{0}$ exists in $E$.

*Corresponding author at: Department of Mathematics, Universitas Sumatera Utara, Medan, 20155, Indonesia

E-mail address: elvina@usu.ac.id 
A sequence $\left(x_{n}\right)$ in $E$ is said order convergent to $x_{0}$ in $E$, if there exists a sequence $\left(p_{n}\right) \subset E$ with $p_{n} \downarrow \vartheta$ and $\left|x_{n}-x_{0}\right| \leq p_{n}$ for each $n$, written as $x_{n} \stackrel{\vartheta}{\longrightarrow} x_{0}$. A sequence $\left(x_{n}\right) \subset E$ is said to be orderCauchy, if there exists $p_{n} \downarrow \vartheta$ in $E$ and $\left|x_{m}-x_{n}\right| \leq p_{n}$ for all $m \geq n \geq 1$. If every order-Cauchy sequence is order convergent, then $E$ is called order-Cauchy complete. For all this notation, we refer to [7]. We shall write $\Omega(E)$ and $\Phi(E)$ for the vector space consisting of all sequences and finitely non-zero sequence from a vector space $E$, respectively.

Furthermore, the collection of all linear operators from a Riesz space $E$ to another Riesz space $F$, denoted by $\mathcal{L}(E, F)$, and the subspace of $\mathcal{L}(E, F)$ consisting of all order bounded operators, denoted by $\mathcal{L}^{b}(E, F)$. The $\sigma$-order continuous operators denoted by $\mathcal{L}^{s o}(E, F)$ and this space is a subspace of $\mathcal{L}^{b}(E, F)$.

Concerning the above spaces, we have

Theorem 1. (see [5])

(i) If $E$ is an order complete, then $\Lambda(E)$ and $\Phi(E)$ is also an order complete.

(ii) The Riesz subspace $\Lambda(E)$ of $\Omega(E)$ order complete if and only if it is ideal in $\Omega(E)$.

Theorem 2. (see [5])

If $\left(T_{n}\right)$ is an increasing or decreasing sequence of operators in $\mathcal{L}^{b}(E, F)$ such that $T_{n} x \stackrel{\vartheta}{\longrightarrow} T x$ for $x \in E$ and for some $T \in \mathcal{L}(E, F)$, then

$$
T \in \mathcal{L}^{b}(E, F) \quad \text { and } \quad T_{n} \stackrel{\vartheta}{\longrightarrow} T \quad \text { in } \quad \mathcal{L}^{b}(E, F) .
$$

\section{Cesàro Operator on Special Case of $\Lambda(E)$}

Let $E$ be a Riesz space, the non-absolute type $E$-valued sequence space is special case of $E$-valued sequence space $\Lambda(E)$, given as follows

$$
\begin{aligned}
& c_{0}(E)=\left\{x=\left(x_{n}\right) \in \Omega(E) \quad \mid \quad x_{n} \stackrel{\vartheta}{\longrightarrow} \vartheta \quad \text { in } \quad E\right\} \\
& c(E)=\left\{x=\left(x_{n}\right) \in \Omega(E) \quad \mid \quad \text { there exists } x_{0} \in E \text { such that } x_{n} \stackrel{\vartheta}{\longrightarrow} x_{0}\right\} \\
& \ell_{\infty}(E)=\left\{x=\left(x_{n}\right) \in \Omega(E) \quad \mid \text { there exists } x_{0} \in E \text { such that } \sup _{n \geq 1}\left\{x_{k}\right\}=x_{0}\right\}
\end{aligned}
$$

It is easy to verify that $E$-valued sequence space $c_{0}(E)$ and $\ell_{\infty}(E)$ are ideals in $\Omega(E)$ and $c(E)$ is a Riesz subspace of $\Omega(E)$. Furthermore, if $x=\left(x_{n}\right) \in \Omega(E)$, the operator $C: \Omega(E) \longrightarrow \Omega(E)$ defined by

$$
\begin{aligned}
C(x) & =\left(x_{1}, \frac{x_{1}+x_{2}}{2}, \cdots, \frac{x_{1}+x_{2}+\cdots+x_{n}}{n}, \cdots\right) \\
& =\left(\frac{1}{n} \sum_{k=1}^{n} x_{k}\right)_{n=1}^{\infty}
\end{aligned}
$$

is called Cesàro Operator. 


\section{Theorem 3.}

Let $E$ be a Riesz space and $x=\left(x_{n}\right) \in \Omega(E)$, then $x \in c_{0}(E)$ if and only if $C(|x|) \in c_{0}(E)$.

Proof.

For proving the necessity. Let $x \in c_{0}(E)$, then $x_{n} \stackrel{\vartheta}{\longrightarrow} 0$, so there exists a sequence $p_{n} \downarrow \vartheta$ in $E$ such that $\left|x_{n}\right| \leq p_{n}$ for each $n$. Since

$$
C(|x|)=\left(\frac{1}{n} \sum_{k=1}^{n}\left|x_{k}\right|\right)_{n=1}^{\infty}
$$

and for every $n \in E$

$$
\frac{1}{n} \sum_{k=1}^{n}\left|x_{k}\right| \leq p_{n}
$$

it follow that

$$
\frac{1}{n} \sum_{k=1}^{n}\left|x_{k}\right| \stackrel{\vartheta}{\longrightarrow} 0
$$

for every $n$. Therefore $C^{\prime}(|x|) \in c_{0}(E)$.

For sufficiency. If $C(|x|) \in c_{0}(E)$, then

$$
\frac{1}{n} \sum_{k=1}^{n}\left|x_{k}\right| \stackrel{\vartheta}{\longrightarrow} 0 \quad \text { in } E
$$

It means, there exists a sequence $p_{n} \downarrow \vartheta$ in $E$ and for every $n$,

$$
\frac{1}{n} \sum_{k=1}^{n} x_{k} \leq \frac{1}{n} \sum_{k=1}^{n}\left|x_{k}\right| \leq p_{n}
$$

So $x=\left(x_{n}\right) \in c_{0}(E)$.

In the similar ways, we could prove the following theorem.

\section{Theorem 4.}

If $x=\left(x_{n}\right) \in \Omega(E)$ and $\Lambda=\left\{c, \ell_{\infty}\right\}, x \in \Lambda(x)$ if and only if $C(|x|) \in \Lambda(x)$.

\section{Order Boundedness}

The proof of the Cesàro operators $C$ on $\Lambda(E)$ order bounded, can be made to depend on the Riesz space $E$ is an order complete.

\section{Theorem 5.}

Let $\Lambda(E)$ be a Riesz subspace of $\Omega(E)$ and $C$ be a Cesàro operator on $\Lambda(E)$, then:

(i) $C \in \mathcal{L}^{+}(\Lambda(E))$

(ii) $C \in \mathcal{L}^{b}(\Lambda(E))$

\section{Proof.}

For $\Lambda=c_{0}$. It is easy to verify (i) to proof point (ii). So, we just prove the point (ii). Since $c_{0}(E)$ is an ideal of $\Omega(E)$, it follow that it is order-Cauchy complete. 
Furthermore, for any $x \in c_{0}(E)$, the Cesàro operator $C$ on $c_{0}(E)$ is a sequence in $E$,

$$
C(x)=\left(\frac{1}{n} \sum_{k=1}^{n} x_{k}\right) .
$$

Since

$$
\frac{1}{n} \sum_{k=1}^{n} x_{k} \leq \sum_{k=1}^{n}\left|x_{k}\right|
$$

and for $x \in c_{0}(E)$

$$
\sum_{k=1}^{n}\left|x_{k}\right| \longrightarrow 0
$$

we can define a sequence

$$
\left(z_{n}\right)=\left(\frac{1}{n} \sum_{k=1}^{n}\left|x_{k}\right|\right)
$$

with $z_{n} \geq 0$ for every $n$.

Define the operator $T_{1}: c_{0}(x) \longrightarrow c_{0}(x)$ by

$$
x \longmapsto T_{1} x=\left(\sum_{k=1}^{n}\left|x_{k}\right|\right)_{n}
$$

Then $T_{1} \in \mathcal{L}^{+}\left(c_{0}(E)\right)$ and for every $x \in c_{0}(E)$

$$
C(x) \leq T_{1}(x)
$$

It means $C \in \mathcal{L}^{r}\left(c_{0}(E)\right)$, that is the Cesàro operator $C$ on $c_{0}(E)$ is a regular operator. Since $c_{0}(E)$ is an order-Cauchy complete, it follow that $C \in \mathcal{L}^{b}(\Lambda(E))$.

For $\Lambda=\ell_{\infty}$, then $\ell_{\infty}(E)$ is an ideal of $\Omega(E)$. If $x \in \ell_{\infty}(E)$ is given, then Cesàro operator

$$
C(|x|)=\left(\frac{1}{n} \sum_{k=1}^{n}\left|x_{k}\right|\right) \in \ell_{\infty}(E) .
$$

Since for every $x \in \ell_{\infty}(E)$

$$
\frac{1}{n} \sum_{k=1}^{n}\left|x_{k}\right| \leq \frac{2}{n} \sum_{k=1}^{n}\left|x_{k}\right|
$$

and if we define the operator $T_{2}: \ell_{\infty}(E) \longrightarrow \ell_{\infty}(E)$ by

$$
T_{2}=\left(\frac{2}{n} \sum_{k=1}^{n}\left|x_{k}\right|\right)_{n=1}^{\infty},
$$

then $T_{2} \in \mathcal{L}^{+}\left(\ell_{\infty}(E)\right)$ and for every $x \in \ell_{\infty}(E)$

$$
C(x) \leq T_{2}(x)
$$

Since $\ell_{\infty}(E)$ is an order-Cauchy complete, then $C \in \mathcal{L}^{b}\left(\ell_{\infty}(E)\right)$. 


\section{Acknowledgement}

The first author is grateful to the second author for the time and opportunity to discuss this small study.

\section{REFERENCES}

[1] A. Brown, P. R. Halmos, and A. L. Shields, "Cesàro operator," Acta Sci. Math. (Szeged), vol. 26, no. 125-137, 1965.

[2] G. Leibowitz, "Spectra of discrete cesàro operator," Tamkang J. Math., vol. 3, pp. 123-132, 1972.

[3] A. A. Albanese, J. Bonet, and W. J. Ricker, "Convergence of arithmetic means of operators in fréchet spaces," Journal of Mathematical Analysis and Applications, vol. 401, no. 1, pp. 160-173, May 2013. [Online]. Available: https://doi.org/10.1016/j.jmaa.2012.11.060

[4] - "The cesàro operator in the fréchet spaces $\ell^{p+}$ and $l^{p-}$," Glasgow Mathematical Journal, vol. 59, no. 2, pp. 273-287, May 2017. [Online]. Available: http: //doi.org/10.1017/S001708951600015X

[5] E. Herawati, Supama, M. Mursaleen, and M. Nasution, "Some characterizations of riesz- valued sequence spaces generated by an order $\varphi$-function," Numerical Functional Analysis and Optimization, vol. 39, no. 1, pp. 38-46, 2018. [Online]. Available: https://doi.org/10.1080/01630563.2017.1351987

[6] K. Yosida, Functional Analysis. Berlin: Springer-Verlag, 1980.

[7] A. C. Zaanen, Introduction to operator theory in Riesz spaces. Springer Science \& Business Media, 2012. 